\title{
B 型烟粉虫的入侵机理与控制基础
}

\section{国家重点基础研究发展计划“农林危险生物入侵机理与控制基础研究”进展}

\author{
(1) 中国农业科学院植物保护研究所, 植物病虫害生物学国家重点实验室, 北京 100094; \\ (2) 浙江大学应用昆虫学研究所, 杭州 310029; \\ (3) 北京市农林科学院植保环保研究所，北京 100089 ; \\ (4) 中国农业科学院蔬菜花卉研究所, 北京 100081 ; \\ (5) 中国农业大学昆虫系, 北京 100094 \\ E-mail: wanfangh@pubcic3.bta.net.cn
}

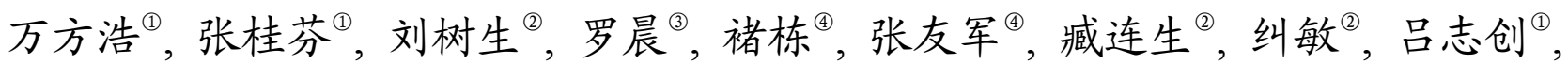

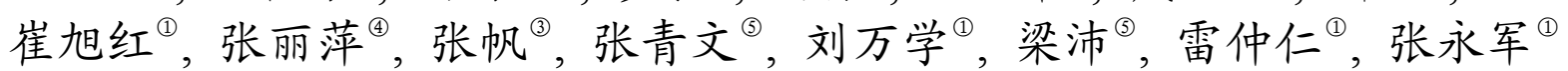

收稿日期: 2007-09-30; 接受日期: 2008-03-18

国家重点基础研究发展计划(批准号: 2009CB119200)资助项目

摘要针对 B 型烟粉竞入侵后的暴发性及生态系统的可侵入性, 开展了 B 型烟粉虫的入侵机 制、成灾机理和控制基础研究. 结果显示, 目前我国至少存在 6 种生物型 (B, Q, ZHJ-1, ZHJ-2, ZHJ-3, FJ-1), 其中 B 型烟粉虫在我国大部分地区、Q 型烟粉虫在我国长江流域已成为优势种 群, 给蔬菜、花卉和棉花生产造成严重危害。寄主植物、地理环境及杀虫剂可诱导 B 型烟粉闽 产生遗传分化, 使其种群遗传结构发生快速演变; 黄瓜和南瓜可诱导羧酸酯酶 (CarE) 和谷胱 甘肽 S-移酶(GSTs)活性升高, 增强 B 型烟粉虫抗药性; 植物次生物可诱导 B 型烟粉虫解毒酶活 性升高. B 型烟粉虫所具有的较强的高温胁迫适应能力和热激蛋白基因的表达与响应密切相关. $\mathrm{B}$ 型烟粉虫可取代土著烟粉䖵，B 型烟粉虫与土著烟粉虫间的非对称交配千扰及其与植物双生 病毒间的互利共生加剧了 B 型烟粉虫的入侵; 特定条件下 B 型烟粉虫可取代温室粉虫, 较强的 逆境适应能力、较快的种群增长力可能是 $\mathrm{B}$ 型烟粉虫取代温室粉虫的主要机制; 较强的对寄主 转换的适应能力与 $\mathrm{B}$ 型烟粉虫寄主谱扩张有关. 土著天敌对 $\mathrm{B}$ 型烟粉虫具有较强的控制潜能; B 型烟粉虫 3, 4 龄若虫及蜜露可诱导丽蚜小蜂产生强烈的搜索行为, 若虫利它素在丽蚜小蜂寄 主搜索和定位中具有重要作用。研究结果为阐明 B 型烟粉虫入侵种群在我国的遗传分化与快 速演变机制和分子生态适应机制、探明种群形成与扩张过程中生态对策的调整及其效应提供了 理论依据，为 $\mathrm{B}$ 型烟粉虫的生物生态控制途径和持续治理策略提供了保障.

烟粉虫(Bemisia tabaci)属同翅目(Homoptera)、粉 䖝科(Aleyrodidae)、小粉闽属(Bemisia), 原产于北非、 中东地区 ${ }^{[1]}$, 是热带、亚热带保护地及大田作物的主 要害虫之一, 寄主范围广泛, 除危害经济作物外, 还

\section{关键词}

入侵生物

B 型烟粉虫

遗传变异

生态机制

可持续控制
危害观赏植物及杂草. 其危害方式主要有 3 种, 一是 取食植物汁液: 烟粉䖝成虫、若虫均刺吸植物韧皮部 汁液, 导致植物衰弱; 同时, 分泌大量蜜露, 污染植 物器官和产品, 诱发煤污病的发生, 使植物光合作用 
受阻 ${ }^{[2]}$. 二是传播病毒: 烟粉虫是许多病毒病的重要 传播媒介, 尤以双生病毒组的病毒最甚，传毒种类多 达 40 余种 ${ }^{[2]}$, 在葫芦科 (Cucurbitaceae) 、豆科 (Leguminosae)、大戟科 (Euphorbiaceae)、锦葵科 (Macvaceae) 及茄科(Solanaceae)上最易传播双生病 ${ }^{\text {毒 }}{ }^{[3]}$; 其次传播长线形病毒组、香石竹病毒组及马铃 薯病毒组的病毒; 此外还可传播其他病毒组的病毒. 通常, 烟粉䖝大暴发后不久, 病毒病随之大发生 ${ }^{[3]}$. 三是引起植物生理异常：烟粉䖝若虫取食后可导致 多种植物生理异常. 例如, 番茄受害严重时出现不规 则成熟，表皮颜色淡化或有条纹; 有时表皮颜色正常， 而内部组织白化、硬化，未成熟 ${ }^{[4]}$. 西葫芦受害后产生 银叶现象，导致植株变白、产品质量下降 ${ }^{[5,6]}$.

截止到 2005 年，世界范围内共描述至少有 26 种 烟粉風生物型 ${ }^{[7-9]}$, 其中 $B$ 型烟粉䖝(biotype B)具有寄 主范围广、存活率高、产卵量大、传播病毒广泛的特 点, 造成的危害最为严重 ${ }^{[1,7]} .20$ 世纪 90 年代, 伴随全 球范围贸易往来的加强, $\mathrm{B}$ 型烟粉虫借助花卉及其他 经济作物苗木成功侵入中国 ${ }^{[10]}$, 相继在许多地区暴 发成灾并造成重大经济损失，对我国农作物和园林 花卉生产构成严重威胁. 目前B型烟粉虫可危害 600 多种田间和温室作物，包括蔬菜、棉花及观赏植物，

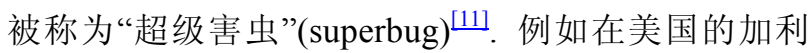
福尼亚、佛罗里达、德克萨斯等地 1991 年和 1992 年 $\mathrm{B}$ 型烟粉虫连续两年大暴发, 分别造成约 2 亿和 5 亿 美元的经济损失 ${ }^{[2]}$; 近几年, B 型烟粉䖝在北京对黄 瓜、番茄、茄子、甜瓜和西葫芦等所造成的损失严重 时可达七成以上 ${ }^{[12,13]}$.

我国对外来生物入侵的研究起步较晚, 关于 $\mathrm{B}$ 型烟粉䖝仅对其分布和种群动态、生物生态学特性、 危害水平和控制技术等进行过研究，而对其暴发的 成因、寄主谱扩张的机理以及可持续治理策略等不甚 明了。鉴于目前烟粉虫种下含有多个正在快速进化 的种群, $\mathrm{B}$ 型烟粉䖝与其他生物型间形态相似，入侵 后极易暴发成灾并导致巨大的经济损失，且难以阻 断其扩张蔓延趋势, 深入研究其入侵种群形成与扩 张的机制，抑制其扩散蔓延、开拓可持续治理技术体 系，成为目前控制与管理 B 型烟粉垕的重大科学问题 与国家需求.

\section{B 型烟粉䖝入侵种群形成与扩张的核心 问题及研究思路}

以 $\mathrm{B}$ 型烟粉䖝入侵后的暴发性为切入点，以其 入侵性与生态系统的可侵入性为核心，围绕 B 型烟粉 風的入侵机制、成灾机理和控制基础，采用分子生物 学、群体遗传学、生物化学以及种群生态学、行为生 态学、系统生态学技术与方法, 集中于种群形成与扩 张的生态适应性、适应新环境的种群分化特性以及可 持续控制的技术基础 3 大问题，从宏观与微观研究相 结合的角度，重点开展以下研究：

（1）针对 B 型烟粉虫在入侵过程中的遗传分化问 题，应用微卫星(SSR)、扩增片段长度多态性(AFLP) 等分子标记方法，研究 B 型烟粉虫的不同地理群体的 遗传结构，以及迁移扩散、自然选择、环境因子和寄 主等对群体遗传分化的影响，揭示入侵过程中种群 系统发育的地理格局与演变机制.

(2) 研究 B 型烟粉虫的生活史特征与种群维持及 扩张的关系，提出种群形成的决定机制.

(3) 研究 B 型烟粉虫与土著非 B 型烟粉虫/温室 粉虫(本地种)/土著天敌等对资源的竞争作用、种间竞 争置换与相互适应或制约的机制，揭示资源机遇、天 敌逃避机遇在 B 型烟粉虫入侵过程中的作用机制，阐 明同一营养阶层 $\mathrm{B}$ 型烟粉竞与土著物种间相互竞争 的机制.

（4）在阐明 B 型烟粉虫入侵与灾变机制的基础上, 明确抑制其种群增长和暴发的关键时期或发育阶段, 研究本地天敌与引进天敌的作用方式、环境友好技术 及其控害潜能，提出相应的生物控制策略和技术体系.

(5) 研究 B 型烟粉竞入侵后与其他因子的相互作 用, 明确抑制种群增长和暴发的关键生态因子, 建立 并提出相应的生态控制策略; 针对 $\mathrm{B}$ 型烟粉䖝已暴 发成灾, 根据系统生态学原理, 研究生物生态协同控 制作用的机制，提出可持续控制途径.

\section{B 型烟粉禹入侵机制与控制基础}

\subsection{B 型烟粉禹入侵种群遗传分化与快速演变}

外来入侵生物的快速遗传分化可能有助于其适 应不同的生境. 研究证实, 入侵我国的 $\mathrm{B}$ 型烟粉虫已 出现遗传分化. 在全国范围内系统采集了烟粉虫，以 分子标记(mtDNA COI)法鉴定指出我国至少存在 6 种 
生物型(B, Q, ZHJ-1, ZHJ-2, ZHJ-3, FJ-1), 其中B型烟 粉虫在我国大部分地区、 $\mathrm{Q}$ 型烟粉虫在我国长江流域 已成为优势种群，给农业生产造成严重危害 ${ }^{[14-17]}$; 田 间胁迫试验直接证实, 寄主植物是诱导 B 型烟粉虫遗 传分化的关键因素，第 10 代与第 5 代各群体间多态 性和杂合度差异测定结果显示, B型烟粉禹的遗传分 化与受胁迫的时间和强度成正相关 ${ }^{[18,19]}$; 对北京、上 海、山东三地黄瓜、番茄上的B型烟粉虫田间种群遗 传多样性的研究证实, 寄主植物以外的环境因子亦 能影响其遗传分化 ${ }^{[18 ~ 20]}$; 杀虫剂的使用会导致B型烟 粉虫种群遗传结构发生快速演变, B型烟粉虫抗性种 群与敏感种群在DNA水平上已存在明显分化，而不 同抗性水平的烟粉竞种群其遗传结构也发生了变异 [18]，B型烟粉䖝抗性种群的遗传结构与抗药性水平有 关. 此外, 杀虫剂的使用能导致 $\mathrm{B}$ 型烟粉䖝入侵种群 遗传结构发生快速演变 ${ }^{[21,22]}$.

寄主植物与B型烟粉䖝杀虫剂敏感性密切相关. 生测结果显示, 取食黄瓜的B型烟粉虫种群对常用杀 虫剂的耐药性明显高于取食南瓜的种群，植物次生 物可诱导 $\mathrm{B}$ 型烟粉䖝解毒酶活性升高. 研究了不同的 寄主植物种类对 $\mathrm{B}$ 型烟粉䖝主要解毒酶活性及动力学 常数(米氏常数 $K_{\mathrm{m}}$ 值)的影响, 发现黄瓜和南瓜可诱导 $\mathrm{B}$ 型烟粉虫羧酸酯酶(CarE) 和谷胱甘肽 $\mathrm{S}$-移酶(GSTs) 活性升高. 进一步研究发现, 不同寄主植物上长期饲 养的 $\mathrm{B}$ 型烟粉禹品系对杀虫药剂的敏感度差异极大, 如灭多威和敌敌畏对黄瓜烟粉虫品系乙酰胆碱酯酶 的 $I_{50}$ 值分别是南瓜品系的 3.5 和 37.1 倍, 黄瓜上烟粉 禹品系CarE的 $I_{50}$ 值分别是南瓜上的 467 倍和 100 倍; 取食黄瓜和西葫芦的烟粉虫其GSTs的 $K_{\mathrm{m}}$ 值分别是取 食南瓜烟粉虫的 1.7 和 1.9 倍 ${ }^{[23]}$. 以含有不同浓度的 檞皮素、2-十三烷酩的人工饲料饲喂B型烟粉禹成虫， $24 \mathrm{~h}$ 后单头测定解毒酶的比活力. 结果表明，0.005\% 和 $0.1 \%$ 槲皮素可诱导 $\mathrm{B}$ 型烟粉䖝 CarE比活力升高; 而当浓度增加到 $1 \%$ 时，则表现为抑制作用. 用 $0.01 \%$ 䚞皮素处理 $\mathrm{B}$ 型烟粉虫, $30 \mathrm{~min}$ 后其体内羧酸酯酶活 性明显增强， $1 \mathrm{~h}$ 后达到最大值. 浓度为 $0.005 \%$, $0.01 \%, 0.1 \%$ 的槲皮素可诱导GSTs活性增强，最高达 $120 \%$. 以 $0.005 \%$ 槲皮素的饲料饲喂 $30 \mathrm{~min}$ 后其GSTs 活性显著升高, 为对照的 8.3 倍. 此后明显降低, 但 仍较对照高 ${ }^{[24]}$.

\subsection{B 型烟粉虫种群扩张的分子生态适应机制}

温度是 $\mathrm{B}$ 型烟粉禹入侵后初始种群建立面临的 主要环境胁迫因子, 研究显示, 较强的生态胁迫适应 能力与 $\mathrm{B}$ 型烟粉虫热激蛋白基因的表达与响应密切相 关. 通过菌落原位杂交篮选热激蛋白基因，得到烟粉 風热激蛋白 $H s p 70$ 和 $H s p 90$ 的全长cDNA序列分别为 $1812 \mathrm{bp}$ 和 $2154 \mathrm{bp}$; 根据cDNA序列设计含酶切位点 的引物, 扩增得到全长序列, 酶切后与带有组氨酸标 签序列的原核载体连接, 构建了烟粉䖝热激蛋白 $H s p 70$ 的原核表达体系，并在宿主中成功表达 ${ }^{[25,26]}$. 通过对 $\mathrm{B}$ 型烟粉禹成虫热激处理获得 $H s p 70$ 片段，同 源性比对显示: $\mathrm{B}$ 型烟粉䖝的 3 个克隆均为 $H s p 70$ 基 因cDNA序列片段(分别为 SB1, SB2 和SB4); 由此推 导出氨基酸序列, 获得大量编码 $H s p 70$ 蛋白的核苷酸 序列, 进一步的比对结果表明与已知的昆虫纲中比 较完整的 $H s p 70$ 家族氨基酸序列相似程度很高, 其中 $\mathrm{SB} 1, \mathrm{SB} 4$ 为诱导型, SB2 为组成型 [26].

\subsection{B 型烟粉虫种群形成与扩张的生态机制}

（1）非对称交配互作促进B型烟粉虫的广泛入侵 及对土著生物型的取代. 非对称交配互作加速了 B 型烟粉虫的入侵及其与土著生物型的竞争取代. 长 期的田间调查、笼罩实验及行为观察证实，在 $\mathrm{B}$ 型烟 粉䖝入侵和取代过程中, 其交配频率增加、雌性后代 比例提高. 连续 3 年的田间调查显示, 由于 $\mathrm{B}$ 型烟粉 䖝的侵入使本地ZHJ1 型烟粉䖝的雌性比率由单独发 生时的 $50 \% \sim 60 \%$ 下降为 $40 \%$ 左右; 而B型烟粉虫的 雌性比率由单独发生时的 $60 \% \sim 70 \%$ 上升为 $80 \%$ 以上, 进而使ZHJ1 型烟粉䖝在浙江部分地区(慈溪、宁波、

温州)于 2005 年即被完全取代 ${ }^{[27]}$.

进一步的室内研究结果表明, 当 $\mathrm{B}$ 型烟粉䖝到 达新的地域与土著烟粉䖝共存时，尽管二者间不能 真正完成交配，但彼此间发生了一系列的求偶行为 及相互作用，使B型烟粉虫的交配频率迅速增加，卵 子受精率提高，后代雌性比例由单独生存时的约 $60 \%$ 提高到 $70 \%$ $80 \%$, 加速了种群增长; 同时, B型 烟粉䖝雄性频频向土著烟粉䖝雌性求爱, 干扰土著 烟粉虫雌雄间的正常交配，使其交配次数降低，后代 雌性比例由单独生存时的约 $50 \%$ 下降到 $20 \%$ 40\%, 使其种群增长严重受阻 ${ }^{[27]}$. 在澳大利亚的昆士兰, 本 
地 $\mathrm{AN}$ 型和 $\mathrm{B}$ 型烟粉闽间种群竞争的田间调查与室内 研究亦显示了类似的趋势[27].

（2）烟粉䖝-双生病毒-寄主植物互作与 $B$ 型烟粉 禹入侵的关系. $\mathrm{B}$ 型烟粉虫与植物双生病毒互利共 生而加剧入侵. 研究表明, B型烟粉風在双生病毒侵染 的植物上持续取食产卵量显著增加、寿命明显延长. 以 $\mathrm{B}$ 型与非B型ZHJ1 烟粉虫为研究对象, 选取 2 种在我 国发生的双生病毒-中国番茄黄化曲叶病毒(tomato yellow leaf curl China virus, TYLCCNV)和烟草曲茎 病毒 (tobacco curly shoot virus, TbCSV), 研究了 TYLCCNV, TbCSV-粉䖝-寄主植物之间的互作. 结果 显示, B型烟粉䖝在双生病毒侵染的植物上持续取食 其产卵量显著增加、寿命明显延长，而且随持续取食 时间的延长，这种有利作用迅速增强; 而非B型ZHJ1 烟粉虫虽可同样高效地传毒，但在双生病毒侵染的 植株上持续取食对其生殖和存活未产生有利影响. 进而表明，寄主植物中双生病毒的感染有利于B型烟 粉䖝种群的繁衍，而这种间接互利关系，可能是近年 来 $\mathrm{B}$ 型烟粉虫在许多地区大发生、竞争取代非 $\mathrm{B}$ 型烟 粉虫并大量传播双生病毒导致病毒病大发生的另一 重要机制[28,29].

（3）B 型烟粉虫与温室粉䖝的竞争取代机制. B 型烟粉虫能以极快的速度取代温室粉禹. 研究证实, 在温室条件下经过 4 7 代的共存竞争，温室粉虫被 B 型烟粉禹完全取代. 种群竞争实验表明，当 $\mathrm{B}$ 型烟 粉禹和温室粉䖝分别以 $20 ： 10,15 ： 15$ 和 $10 ： 20$ 对 (雌雄性比 $1: 1$ ) 的比例于温室适宜条件下在番茄上 连续多代共存时, 4,5 和 6 代后温室粉虫被 B 型烟粉 融完全取代; 期间 $\mathrm{B}$ 型烟粉虫种群增长速率分别为 起始种群的 13.4, 12.4 和 17.0 倍, 而温室粉虫的种群 数量随两种粉虫共存世代的增加而下降. 单独生存 (15 对, 雌雄性比 $1 ： 1$ ) 实验结果显示, $\mathrm{B}$ 型烟粉虫种 群增长能力较温室粉䖝强, 在番茄上连续饲养 7 代, $\mathrm{B}$ 型烟粉虫种群增长了 10.9 倍, 而温室粉虫仅增长了 4.7 倍. 此外, B 型烟粉䖝雌性比例较温室粉䖝高, 单 独生存或与温室粉䖝共存, B 型烟粉䖝的雌雄比率分 别为 1.62 和 1.69 , 而温室粉䖝为 1.20 和 1.43 .

较强的种群形成能力可能是 $\mathrm{B}$ 型烟粉䖝竞争取 代温室粉䖝的主要机制. 研究发现, B 型烟粉虫较温 室粉䖝发育历期短、繁殖能力强. 基础生物学特性比
较研究表明, 在番茄、烟草和棉花上单独饲养两种粉 䖝，B型烟粉虫的发育历期分别为 21.2，24.3 和 26.6 天，而温室粉䖝分别为 $22.1,28.7$ 和 30.2 天; 尽管两 种粉䖝在番茄上的发育历期没有明显差异，但在烟 草和棉花上温室粉虫的发育历期较 $\mathrm{B}$ 型烟粉虫的 长 ${ }^{[30]}$. 以番茄为寄主饲养两种粉虫，B型烟粉虫的繁 殖能力较温室粉䖝的强; 当 $\mathrm{B}$ 型烟粉意单独生存或与 温室粉虫混合发生时，其单雌产卵量分别为 278 粒和 251 粒，而温室粉䖝分别为 74 粒和 54 粒. 利用刺吸 电波图技术研究了B型烟粉虫和温室粉虫在甘蓝上的 取食行为, B型烟粉䖝记录到 7 种波形, 温室粉虫只记 录到刺探波形，少有取食波形，说明 $\mathrm{B}$ 型烟粉虫对寄 主的适应性比温室粉䖝强 [31].

B型烟粉風具有较强的温度逆境适应能力, 在其 种群形成和扩张中具有重要意义. 比较研究显示, B 型烟粉䖝具有较强的抵抗高温逆境的能力, 而逐渐 扩大的保护地面积为 $\mathrm{B}$ 型烟粉虫抵御低温逆境、延续 种群提供了场所. 室内研究表明, B型烟粉颯成虫耐热 能力较温室粉蛗强, 其耐热阈值分别为 $45^{\circ} \mathrm{C}$ 和 $43^{\circ} \mathrm{C}$; 不同高温逆境下 $\mathrm{B}$ 型烟粉䖝成虫繁殖力相当, 而温室 粉蛔明显受挫; 温度升高对两种粉䖝后代孵化均有 不良影响, 高温使温室粉䖝后代性比明显降低 $\left.{ }^{[32} 34\right]$. 低温逆境实验结果显示, 温室粉禹对低温的耐受能 力较 $\mathrm{B}$ 型烟粉䖝强; $\mathrm{B}$ 型烟粉䖝成虫对低温逆境最为 敏感，而拟蛹抵抗低温的能力最强长达 10 天. 在 $2^{\circ} \mathrm{C}$ 条件下 3 天后B型烟粉䖝成虫死亡率为 $90 \%$ ，而温室 粉䖝的存活未受影响; $2^{\circ} \mathrm{C}$ 时 $\mathrm{B}$ 型烟粉䖝卵及 $1 \sim 3$ 龄若 虫的耐受极限为 6 天, 而温室粉䖝长于 8 天. $24^{\circ} \mathrm{C}$ 下, $\mathrm{B}$ 型烟粉虫成虫寿命及繁殖能力较温室粉虫强, 当温 度降至 $15 \sim 21^{\circ} \mathrm{C}$ 时, B型烟粉䖝成虫寿命缩短 5 11 天、 繁殖力下降 $31 \% \sim 62 \%$; 在 $15^{\circ} \mathrm{C}$ 和 $18^{\circ} \mathrm{C}$ 下，成虫前历 期分别延长 28 和 20 天，存活率低于 $20 \%$ ，几无雄性 个体生存 ${ }^{[35]}$, 阐明了在华北地区冬季温室中温室粉 垕为优势种的主要原因; 而 $\mathrm{B}$ 型烟粉䖝在华北地区保 护地种植面积不断扩大和自身所具有的较强的种群 增长能力及对高温逆境的强适应性的共同作用下, 使自身种群不断扩大并最终形成危害.

对转换寄主较强的适应能力可能是 B 型烟粉䖝 寄主谱扩张的主要原因. 研究证实, 改变寄主植物种 类对 $\mathrm{B}$ 型烟粉䖝消化酶活性和比活力没有明显影响. 
以番茄为对照寄主，以甘蓝、棉花和玉米为转换寄主, 对 B 型烟粉風和温室粉䖝在寄主转换过程中 2 64 h 消化酶系的动态变化进行了系统研究. 结果表明, 在 非寄主玉米上取食 $\mathrm{B}$ 型烟粉蛗较温室粉蛗海藻糖含量 和海藻糖酶比活力的恢复能力强、稳定性能好. 改变 植物种类, B型烟粉風淀粉酶比活力抑制-激活需时短 且多有波动，而温室粉虫抑制-激活需时长且较为平 缓 ${ }^{[36]}$; 随取食时间的延长, B型烟粉風蛋白质的累积 量波动上升, 而温室粉虫却缓慢下降; 此外, $\mathrm{B}$ 型烟 粉竞的蛋白酶比活力对寄主转换无明显反应，而在 棉花和玉米上温室粉蛔蛋白酶比活力显著降低. 进 而表明，B型烟粉䖝在由嗜食寄主转移到非嗜食乃至 非寄主的过程中，经历短期的适应即可获取足够的 营养, 从而使种群得以延续和扩张.

（4）B型烟粉虫与非B型烟粉虫的竞争取代机制.

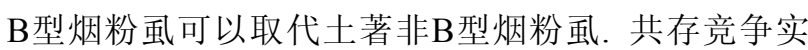
验证实, 经过 2 6代非B型完全被B型烟粉虫替代, 寄 主植物种类不同其适合度各异，当两种生物型在棉 花或西葫芦上以相同初始数量共存竞争时, 分别经 过 6 代或 2 代非B型完全被B型替代. 在棉花上，即使 以非B型占 $87 \%$ 开始共存, 225 天后，非B型也完全被 $B$ 型替代. 说明 $B$ 型烟粉禹具有在短期内竞争取代浙 江非B型烟粉禹的能力 ${ }^{[37]}$. B型和ZHJ-2 型烟粉䖝发 育、存活和生殖特性测定结果显示, 在棉花上, 二个 生物型的适合度相当; 在烟草和西葫芦上, B型的适 合度较高; 而在菜豆和辣椒上, ZHJ-2 型的适合度较 高 $[38]$.

\subsection{B 型烟粉風可持续控制策略与途径}

在阐明 $\mathrm{B}$ 型烟粉禹入侵与灾变机制的基础上, 结合抑制其种群增长和暴发的关键时期或发育阶段, 重点研究土著天敌与引进天敌的作用方式、环境友好 技术及其控害潜能，提出相应的生物生态控制策略 及技术体系。

(1) 土著捕食性天敌对 B型烟粉䖝的控害效能. 土著捕食性天敌昆虫对 $\mathrm{B}$ 型烟粉虫具有较强的控制能 力. 分子标记技术研究表明, 漂虫(Propylaea japonica, Harmonia axyridis, Scymnus hoffmanni, Coccinellid septempunctata)、草蛉(Chrysopa pallens, Chrysopa Formosa)、花蝽(Orius sauteri)及蜘蛛(Erigonnidium graminicolum, Neoscona doenitzi) 、捕食螨
(Typhlodromips swirskii) 等均可捕食烟粉虫, 为烟粉 䖝的生物控制提供了物质基础. 分别以 SCAR分子标 记、TaqMan实时荧光定量PCR技术检测了棉田主要 捕食性天敌对 $\mathrm{B}$ 型烟粉䖝的捕食能力 ${ }^{[39]}$. 在棉田有大 量棉蚜Aphis gossypii与烟粉虫共存时, 漂虫、草蛉、 花蝽、蜘蛛等均可捕食烟粉䖝 $[40]$, 其对烟粉䖝的捕食 能力以拟蛹计为 $0.8 \sim 18.8$ 头; 其中, 漂虫和草蛉幼虫 以及蜘蛛和小花蝽成虫对烟粉颯的捕食能力较强 ${ }^{[41]}$. 已知捕食螨和 Euseius scutalis能够抑制单株黄瓜上 的烟粉虫种群; 温室内生物学和生态学研究表明, 两 种捕食螨均能区分有无B型烟粉虫的植株，捕食螨对 $\mathrm{B}$ 型烟粉䖝虫害植株气味的反应受捕食螨与虫害植株 经历的影响, 捕食螨在温室中向虫害植株的聚集主 要由虫害植株和清洁植株对捕食螨不同的滞留作用 所致 $[42,43]$.

(2) 植物-B型烟粉禹-丽蚜小蜂三级互作行为的 化学生态机制. 粉虫蜜露是其寄生性天敌搜索的主 要利它素源. 对 $\mathrm{B}$ 型烟粉虫和温室粉虫蜜露利它素成 分的分析显示, 两种粉虫在不同寄主植物上的蜜露 均富含糖和氨基酸, B型烟粉䖝 3,4 龄若虫及蜜露可 诱导丽蚜小蜂产生强烈的搜索行为. 以离子色谱技 术分别对甘蓝与黄瓜上B型烟粉虫以及黄瓜上温室粉 虫蜜露中糖和氨基酸组分和含量进行了比较研究, 结果表明两种粉䖝在不同寄主植物上的蜜露均富含 糖和氨基酸, 其中糖占优势; 寄主植物和粉虫种类影 响蜜露中糖和氨基酸的组成和含量. 甘蓝上 $\mathrm{B}$ 型烟粉 䖝蜜露中以二糖和丙氨酸占优势, 黄瓜上两种粉禹 蜜露中以三糖和四糖为主 ${ }^{[44]}$. 以 GC-MS法对蜜露和若 虫挥发性利它素的分析结果表明, B型烟粉䖝 3,4 龄若 虫及蜜露可诱导丽蚜小蜂产生强烈的搜索行为, 近距 离时表现出明显的正趋向性和选择性; 蜜露中的利它 素仅在丽蚜小蜂寄主搜索行为中具有导向作用, 而在 寄主定位中无作用; B型烟粉䖝 3,4 龄若虫中的利它素 则在丽蚜小蜂寄主搜索和定位中具有重要作用 ${ }^{[45]}$.

\section{3 热点问题讨论}

目前 B 型烟粉虫在我国大部分地区已暴发成灾, 尽管我们在 $\mathrm{B}$ 型烟粉虫种群形成、扩张和变异等研 究中取得了重大突破, 然而由于烟粉虫具有较强的 逆境胁迫适应能力, 在种群形成与扩张过程中极易 产生遗传分化. 因此为了对烟粉虫进行长期有效的 
可持续治理，尚需加强以下各方面的研究.

\section{1 我国烟粉虫生物型及其快速鉴定技术}

mtDNA COI 标记技术研究显示, 我国至少有 6 种生物型, 即 B, Q, ZHJ-1, ZHJ-2, ZHJ-3, FJ-1. 其中 $\mathrm{B}$ 型烟粉虫在我国大部分地区、 $\mathrm{Q}$ 型烟粉虫在我国长 江流域已成为优势种群, 给蔬菜、园林花卉及棉花生

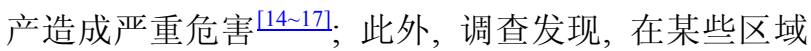
$\mathrm{Q}$ 型烟粉䖝已取代了 $\mathrm{B}$ 型烟粉䖝 ${ }^{[17]}$. 然而, 目前各生 物型的起源尚未明确, 不同生物型在我国的分布、寄 主范围、危害程度、种群形成、扩张趋势及扩张机制 尚不明了, 各区域烟粉䖝生物型的群体结构、各生物 型间的遗传关系尚未明晰; 同时, 烟粉䖝生物型的快 速鉴定技术与方法尚不成熟. 因此，在明确烟粉虫生 物型和遗传结构的基础上, 发展烟粉虫生物型快速鉴 定技术，并应用于监测和检测烟粉襁各生物型的实时 动态、扩张趋势, 是阐明烟粉禹群体遗传分化和遗传 结构，建立烟粉虫早期预警和风险评估体系，提出烟 粉䖝预警与预防、检测与可持续控制科学对策的关键.

为了解决上述关键问题，我国政府在 “十一五” 期间将 “入侵物种快速检测与监测技术” 课题纳入国 家科技支撑计划，针对烟粉䖝体型小且各生物型间 形态相似，及传入途径的不确定性，首先开展了 $\mathrm{Q}$ 型 烟粉虫快速检测技术研究并取得重要进展，为烟粉 䖝生物型的实时监测提供了技术保障. 鉴于烟粉虫 生物型及其遗传结构的复杂性和科学的重要性, 有 必要开展烟粉虫的种群系统发育地理格局与演变的 研究.

\section{$3.2 B$ 型烟粉闽逆境生物学}

研究表明, B型烟粉虫雌性较雄性的耐热性强, $43^{\circ} \mathrm{C}$ 和 $45^{\circ} \mathrm{C}$ 的短时高温胁迫使 $\mathrm{B}$ 型烟粉虫后代的雄 性比例增加; 相同条件下, $\mathrm{B}$ 型烟粉䖝的耐热性高于 温室粉禹 ${ }^{[32]}$; 局部区域已出现了 $\mathrm{Q}$ 型取代 $\mathrm{B}$ 型烟粉
風 ${ }^{[17]}$; 在菜豆(greenbean)上温室粉䖝和烟粉禹难以长 期共存, 且温室粉䖝为优势种群 ${ }^{[46]}$. 因此从分子生 物学和逆境生物学层面, 解释我国烟粉䖝生物型的 种类和分布与其耐热性的关系以及 $\mathrm{B}$ 型烟粉虫不同 地理种群的耐热性差异, 探讨 Hsp 70 表达在生殖适应 性降低中所起的作用，阐明 $\mathrm{B}$ 型烟粉䖝和温室粉虫耐 热性差异的原因，明确 $\mathrm{B}$ 型烟粉虫和温室粉䖝在全球 变化的大环境下其地域分布和种群动态存在差异的 机制, 解析 $\mathrm{B}$ 型和 $\mathrm{Q}$ 型烟粉䖝竞争互作的抗性机制并 对其抗性进行跟踪监测, 预测哪种粉虫或何种烟粉 虫生物型在长期的适应进化过程中将占据优势地位、 成为优势物种/种群，对揭示生物入侵过程中的分子 生态适应机制和逆境生物学机制意义重大.

\section{3 环境胁迫与 $\mathrm{B}$ 型烟粉虫的遗传分化}

田间胁迫实验直接证实，寄主植物、地理环境、 杀虫剂是诱导B型烟粉風遗传分化的关键因素 [19 21], 寄主植物的种类和品系均会使 $\mathrm{B}$ 型烟粉䖝对杀虫剂的 敏感性发生改变 ${ }^{[23]}$. 因此, 采用功能基因组学方法 (expressed sequence tags, EST)研究B型烟粉虫对环境 胁迫的响应、与生态适应相关基因的表达与调控，以 及生态胁迫诱导相关蛋白的功能, 揭示B型烟粉虫新 致害类群形成的遗传基础及其对环境生态适应的过 程与机理，探明 $\mathrm{B}$ 型烟粉虫扩张过程中生态对策的调 整及其效应，是构建烟粉䖝生物生态可持续控制体 系的基础.

\section{4 同域猎物对土著天敌捕食烟粉虫的干扰}

针对捕食性天敌在田间可以捕食多种猎物的特 点，在现有技术体系的基础上建立多重 PCR 技术体 系，明确其他猎物对天敌捕食烟粉虫是否存在干扰， 干扰作用大小，田间检测效果评价等，是篮选烟粉虫 功能天敌、制定入侵生物可持续控制策略和技术体系 的理论基础.

\section{参考文献}

1 Brown J K. The sweet potato or silverleaf whiteflies: biotypes of Bemisia tabaci or a species complex. Ann Rev Entomol, 1995, 40: $511-534[\mathrm{DOI}]$

2 Oliveira M R V, Henneberry T J, Anderson P. History, current status, and collaborative research projects for Bemisia tabaci. Crop Protect, 2001, 20(9): 709-723[DOI]

3 Bedford I D, Briddon R W, Brown J K, et al. Geminivirus transmission and biological characterization of Bemisia tabaci (Gennadius) 
biotypes from different geographic regions. Ann Appl Biol, 1994, 125: 311-325[DOI]

4 Schuster D J, Mueller T F, Kring J B, et al. Relationship of the sweetpotato whitefly to a new tomato fruit disorder in Florida. HortSci, 1990, 25: $1618-1620$

5 Segarra-Carmona A E, Bird J, Escudero J. Silvering of Cucurbita moschata (Duchesne Poir) associated with Bemisia tabaci Genn. (Homoptera: Aleyrodidae) in Puerto Rico. J Agr Univ Puerto Rico, 1990, 74: 477—478

6 Yokomi R K, Hoelmer K A, Osborne L S. Relationship between the sweetpotato whitefly and the squash silverleaf disorder. Phytopathol, 1990, 80: 895-900[DOI]

7 Perring T M. The Bemisia tabaci species complex. Crop Protect, 2001, 20(9): 725—737 [DOI]

8 Simon B, Cenis J L, Demichelis S, et al. Survey of Bemisia tabaci (Hemiptera: Aleyrodidae) biotypes in Italy with the description of a new biotype (T) from Euphorbia characias. Bul Entomol Res, 2003, 93: 259-264

9 Delatte H, Reynaud B, Granier M, et al. A new silverleaf-inducing biotype Ms of Bemisia tabaci (Hemiptera: Aleyrodidae) indigenous to the islands of the south-west Indian Ocean. Bul Entomol Res, 2005, 95: 29-35

10 罗晨，姚远，王戎疆，等。利用 mtDNA COI 基因序列鉴定我国烟粉虫的生物型。昆虫学报, 2002, 45(6): 759-763

11 Barinaga M. Is devastating whitefly invader really a new species? Science, 1993, 259: 30[DOI]

12 罗晨, 张君明, 石宝才, 等. 北京地区烟粉虫 Bemisia tabaci (Gennadius) 调查初报. 北京农业科学, 2000, 增刊(烟粉虫专辑): $42-47$

13 石宝才, 罗晨, 张君明, 等. 12 种药剂对烟粉虫 Bemisia tabaci 田间药效试验. 北京农业科学, 2000, 增刊(烟粉虫专辑): 4854

14 褚栋, 张友军, 丛斌, 等. 烟粉虫不同地理种群的 mtDNA COI 基因序列分析及其系统发育. 中国农业科学, 2006, 38: 76一 85

15 Chu D, Zhang Y J, Brown J K, et al. The introduction of the exotic Q biotype of Bemisia tabaci from the Mediterranean region into China on ornamental crops. Florida Entomol, 2006, 89(2): 168 - 174 [DOI]

16 Li Z X. Molecular phylogenetic analysis reveals at least five genetic races of Bemisia tabaci in China. Phytoparasitica, 2006, 34(5): 431440[DOI]

17 徐婧, 王文丽, 刘树生. Q 型烟粉虫在浙江局部地区大量发生危害。植物保护, 2006, 32(4): 121

18 张丽萍. 外来入侵烟粉虫的种群动态、遗传分化及对噻虫嗪的抗性分子机理研究. 博士学位论文. 北京: 中国农业大学, 2005

19 Zhang L P, Zhang Y J, Zhang W J, et al. Analysis of genetic diversity among different geographical populations and determination of biotypes of Bemisia tataci in China. J Appl Entomol, 2005, 129(3): 121-128[DOI]

20 褚栋，刘国霞，范仲学，等。烟粉虫复合种不同地理种群的遗传分化。昆虫学报, 2006, 49(4): 687-694

21 藏连生, 傅荣幸, 刘树生, 等. B 型与浙江非 B 型烟粉虫药剂敏感性比较. 昆虫知识, 2006, 43(2): 207-210

22 褚栋, 万方浩, 肖利锋, 等. 施用噻虫嗪可降低 B 型烟粉虫群体的遗传多样性. 昆虫学报, 2008, 51(2): 150-154

23 Liang P, Cui J Z, Yang X Q, et al. Effects of host plants on insecticide susceptibility and carboxylesterase activity in Bemisia tabaci biotype B and greenhouse whitefly, Trialeurodes vaporariorum. Pest Manag Sci, 2007, 63: 365-371[DOI]

24 牟少飞, 梁沛, 高希武. 檞皮素对 B 型烟粉虫羧酸酯酶和谷胱甘肽 S-转移酶活性的影响. 昆虫知识, 2006, 43(4): 491一 -495

25 王海鸿. B 型烟粉虫热休克蛋白基因的克隆和表达及其与胁迫耐受性关系的研究. 博士学位论文. 北京: 中国农业科学院研 究生院, 2005

26 崔旭红. B 型烟粉虫和温室粉虫热胁迫适应性及其分子生态机制. 博士学位论文. 北京: 中国农业科学院研究生院, 2007

27 Liu S S, De Barro P J, Xu J, et al. Asymmetric mating interactions drive widespread invasion and displacement in a whitefly. Science, 2007, 318: 1769-1772[DOI]

28 纠敏, 周雪平, 刘树生. B 型烟粉虫携带传播烟草曲茎病毒的能力. 植物保护学报, 2006, 33(2): 168一172

29 Jiu M, Zhou X P, Tong L, et al. Vector-virus mutualism accelerates population increase of an invasive whitefly. PLoS ONE, 2007, 2(1): e182. doi:10.1371/journal.pone. 0000182[DOI]

30 罗晨, 郭晓军, 岳梅, 等. 寄主植物对 B 型烟粉虫形态学和生物学特性的影响. 生物多样性, 2006, 14(4): 333-339

31 高庆刚, 罗晨, 郭晓军, 等. 烟粉虫和温室粉虫在甘蓝上的刺探取食行为比较. 昆虫知识, 2006, 43(6): 802-805

32 Cui X H, Wan F H, Xie M, et al. Effects of heat shock on survival and fecundity of two whitefly species: Trialeurodes vaporatiorum and Bemisia tabaci biotype B. 10pp. J Insect Sci, 2008, 8: 24, available online: insectscience.org/8.24

33 崔旭红, 谢明, 万方浩. 短时高温暴露对 B 型烟粉虫和温室粉虫存活以及生殖适应性的影响. 中国农业科学, 2008, 41(2): 424430

34 崔旭红, 谢明, 万方浩. B 型烟粉虫和温室白粉虫逆境条件下的生存特性. 昆虫学报, 2008, 51(in press) 
35 陈艳华, 崔旭红, 谢明, 等. B 型烟粉虫和温室白粉虫在低适温区条件下的生长繁殖特性研究. 中国生态农业学报, 2009,5

36 雷芳, 张桂芬, 万方浩, 等. 寄主转换对 B 型烟粉虫和温室粉虫海藻糖含量和海藻糖酶活性的影响. 中国农业科学, 2006, 39(7): $1387-1394$

37 藏连生, 刘树生, 刘银泉, 等. B 型烟粉虫与浙江非 B 型烟粉虫的竞争. 生物多样性, 2005, 13(3): 181-187

38 Zang L S, Chen W Q, Liu S S. Comparison of performance on different host plants between the B biotype and a non-B biotype of Bemisia tabaci from Zhejiang, China. Entomol Exp Appl, 2006, 121: 221-227 [DOI]

39 吕志创, 张桂芬, 万方浩，等。天敌对烟粉虫捕食作用的 SCAR 标记检测。中国农业科学, 2005, 38(6): 1167一-1173

40 Zhang G F, Lü Z C, Wan F H. Detection of Bemisia tabaci remains in predator guts using a sequence-characterized amplified region marker. Entomol Exp Appl, 2007, 123(1): 81-90[미]

41 Zhang G F, LüZh C, Wan F H, et al. Real-time PCR quantification of Bemisia tabaci (Homoptera: Aleyrodidae) remains in predator guts. Mol Ecol Note, 2007, 7: 947-954 [DOI]

42 Nomikou M, Meng R X, Schraag R, et al. How predatory mites find plants with whitefly prey. Exp Appl Acarol, 2005, 36: 263$275 \underline{\text { [DOI] }}$

43 Meng R X, A Janssen, M Nomikou, et al. Previous and present diets of mite predators affect antipredator behaviour of whitefly prey. Exp Appl Acarol, 2006, 38: 113-124 [DOI]

44 刘万学, 杨勇, 万方浩, 等. 甘蓝与黄瓜寄主上 B 型烟粉虫和温室白粉虫蜜露糖分、氨基酸和挥发物组分的比较分析. 昆虫 学报, 2007, 50(8): 850-857

45 刘万学, 杨勇, 万方浩，等。丽蚜小蜂对 B 型烟粉虫不同利它素源的行为反应。中国生物防治, 2008, 24(2): 97一-102

46 Liu T X, Oetting R D, Buntin G D. Evidence of interspecific competition between Trialeurodes vaporariorum (Westwood) and Bemisia tabaci (Gennadius) (Homoptera: Aleyrodidae) on some greenhouse-grown plants. J Entomol Sci, 1994, 29: 55-65 